\section{TURISMO AMBIENTAL - CONHECENDO A REALIDADE DA UNIDADE DE CONSERVAÇÃO PARQUE ESTADUAL DA PEDRA BRANCA, SEDE PAU DA FOME - RJ}

\author{
ENVIRONMENTAL TOURISM - GETTING TO \\ KNOW THE REALITY IN A CONSERVATION UNIT \\ - PEDRA BRANCA STATE PARK - PAU DA FOME \\ HEADQUARTERS - RJ
}

\section{RESUMO}

$\mathrm{O}$ artigo busca interpretar e pesquisar o desenvolvimento do turismo em uma unidade de conservação, tendo como objeto de estudo o Parque Estadual da Pedra Branca - PEPB, que está localizado no bairro da Taquara no Município do Rio de Janeiro - RJ. No trabalho, destaca-se a importância das Unidades de Conservação (UCs) para o lazer da sociedade, em que é apresentada uma leitura das principais carências e dificuldades enfrentadas para a gestão dessas áreas. Para essa proposição, utilizou-se como metodologia a revisão de literatura, associada à pesquisa exploratória, tendo a participação ativa dos autores nas reuniões da câmara de uso público. Os resultados obtidos, após o trabalho de registro com fotografia e caminhadas, demonstraram o quanto a visitação ainda é bastante incipiente, se comparada ao grande potencial do PEPB. Para tal, discutiu-se sobre formas de turismo, o qual possibilita contato junto à natureza, ressaltando ainda a importância do ecoturismo e do planejamento da atividade para a obtenção da sustentabilidade.

Palavras-chave: Parques. Turismo ambiental. Perfil de visitante. Ecoturismo e unidade de conservação.

\begin{abstract}
The article seeks to interpret and research the development of tourism in a conservation unit, having as object of study the State Park of Pedra Branca - SPPB, which is located in the district of Taquara in the city of Rio de Janeiro - RJ. The work highlights the importance of the Conservation Units (CUs) for the leisure of society, in which a reading of the main needs and difficulties faced for the management of these areas is presented. For this proposi-
\end{abstract}


tion, the literature review was used as a methodology. The research was exploratory, with the active participation of the authors in the meetings of the chamber of public use. The results obtained, after the work of registration with photography and hiking, showed how much visitation is still incipient compared to the great potential of SPPB. For this purpose, it was discussed forms of tourism, which allows contact with nature, emphasizing also the importance of ecotourism and the planning of the activity to achieve sustainability.

Keywords: Parks. Environmental tourism. Visitor's profile. Ecotourism and conservation unit.

\section{INTRODUÇÃO}

Segundo a Organização Mundial do Turismo (1999), os turistas do século 21 não se satisfazem apenas em contemplar, de forma passiva, os atrativos turísticos, assim como não se limitam ao binômio sol e praia. Ao contrário, investem em produtos e serviços mais qualificados e estruturados o que, geralmente, exige um gasto médio mais alto, se caracterizando como um novo estilo de fazer turismo e de empregar o tempo livre.

O Brasil, apesar de apresentar características naturais favoráveis ao desenvolvimento do turismo, como um extenso litoral, regiões de serras com clima tropical de altitude, o Pantanal Mato-grossense e suas belezas naturais, além da Região Amazônica, tem dedicado pouca importância a essa atividade, não havendo grandes investimentos da divulgação do país no exterior. Além disso, o país ocupa uma inexpressiva posição na classificação no ranking dos países mais visitados do mundo, conforme dados apresentados a seguir.

No Fórum Econômico Mundial - FEM, realizado no ano de 2017, na avaliação de competitividades de viagens e turismo, o Brasil ocupava a 27 a posição no ranking mundial, posição acima do último relatório, que demonstrava que o país havia recebido 6.578.074 turistas no ano de 2016. Fomentando essa informação, no Plano Nacional do Turismo - PNT (2018-2022) entendido como aquele que estabelece diretrizes e estratégias para se vislumbrar o futuro do turismo no Brasil, o país continuava a ocupar a 27 a posição mundial, apresentando pequenas variações: em 2017, contabilizava um fluxo de 6.588.770 e, em 2018, 6.621.376 turistas, segundo informações obtidas no site do Ministério do Turismo - Mtur - Anuário estatísticos de 2019, ano base 2018 .

Já em pesquisa anual realizada pela Organização Mundial de Turismo - OMT, o Brasil, em 1997, ocupava a 39ª posição do referido ranking, liderado pela França, que recebeu cerca de 67.310.000 turistas, seguida pelos Estados Unidos, que receberam 47.752.000 turistas internacionais. Tais números são de extrema importância, pois, na sociedade moderna, a atividade turística é vista como um movimento peculiar e marcante economicamente, sendo considerado um dos aspectos centralizadores na busca por promover o desenvolvimento e a transformação dos territórios em que a atividade é realizada.

No Brasil, esse cenário não se modifica. Segundo Fideles (2016), a cidade do Rio de Janeiro, que é considerada uma das principais portas de entrada de turistas estrangeiros no país, recebeu aproximadamente, $34 \%$ da fatia desse mercado no país. A cidade possui diversos atrativos e, no cenário de paisagens naturais, encontram-se diversas áreas urbanas protegidas, manejadas conforme objetivos de conservação, ou seja, que permitem o desenvolvimento de ações de educação ambiental e de atividades voltadas a atividades contemplativas e recreativas.

É nesse contexto que Ruschmann (2004) sugere que o grande consumidor da contemporaneidade é o turismo. A autora complementa que sua evolução, nas últimas décadas, teve fator desenvolvedor a "busca" do verde e a "fuga" dos blocos urbanos pelas pessoas, pessoas estas que vêem na atividade a tentativa de recuperar o equilíbrio psicofísico em contato com a natureza. 
Entre essas áreas naturais existentes na cidade do Rio de Janeiro, destaca-se aqui o Parque Estadual da Pedra Branca - PEPB. Muitas das atividades de uso público realizadas no parque relacionam-se ao lazer, envolvendo, especialmente, caminhadas em trilhas, contemplação da natureza, montanhismo e banhos de cachoeiras, sendo estas aliadas ao desenvolvimento de ações de educação ambiental. Todas essas atividades estão sujeitas às normas e às restrições estabelecidas no Decreto Estadual 42.483/2010, que disciplina o uso público nos parques estaduais administrados pelo Instituto Estadual do Ambiente - INEA (RIO DE JANEIRO, 2010).

Sua localização geográfica, unida às suas características geomorfológicas, proporciona aos visitantes pontos de observação privilegiados da cidade, entre eles o mirante da Pedra da Ponte, da Pedra Rosilha, de Grumari, do Pico da Piraquara, Monte Alegre e da Pedra do Quilombo. Além disso, abriga o Pico da Pedra Branca, ponto culminante da cidade, tendo 1.024 metros de altitude. Além dos mirantes, a unidade de conservação abriga nascentes, rios, riachos, poços e cachoeiras, sendo eles: o Poço das Pedras, o Poço da Mãe d' Água, do Camorim, do Mucuíba, da Batalha e Quinino e do Véu da Noiva, formando paisagens singulares.

Levando-se em consideração esses atributos, este artigo tem por objetivo apresentar as atividades desenvolvidas no PEPB e as ações previstas por sua gestão em prol da sustentabilidade desse uso público. Quanto aos procedimentos e métodos adotados, segundo Vergara (2003), esta pesquisa pode ser considerada exploratória quanto aos fins, como também descritiva, ao expor perfis e percepções de atores locais sobre a visitação na comunidade pelo fato de abrir questões em área acúmulo e pouco conhecimento.

O estudo iniciou-se por meio da visita exploratória e técnica ao PEPB realizada pelos autores. Nessa visita foi verificada a dimensão e a estrutura do parque. Deu-se início à participação dos autores, de forma voluntária e ativa, nas reuniões da câmara de uso público, promo- vidas pelo PEPB. Por se tratar da revisão bibliográfica, foram utilizados materiais eletrônicos, livros e revistas de cunho científico; entre eles, a Revista Brasileira de Ecoturismo, Revista Brasileira de Educação Ambiental Social e Ecológica, Caderno Virtual de Turismo, Revista Brasileira de Ecoturismo, Revista Brasileira de Pesquisa em Turismo, Revista Acadêmica Observatório Inovação do Turismo, Revista Turismo em Análise; além de leis, decretos e guias das unidades de conservação.

Durante a busca por referencial teórico nas revistas citadas, foram utilizados os seguintes termos de busca: turismo ambiental, ecoturismo, unidade de conservação, sustentabilidade, turismo e lazer, impacto ambiental, uso público, proteção da natureza, planejamento, percepção ambiental, impactos socioculturais e políticas públicas de turismo. Após essa pesquisa, foram encontrados e selecionados 35 artigos científicos, com o objetivo de verificar se a pesquisa realizada já havia sido feita anteriormente, ou alguma outra com temática similar.

No que tange ao objeto de estudo, o Parque Estadual da Pedra Branca - PEPB foi utilizado na qualidade de estudo de caso que busca embasar a discussão sobre a importância de uso público em áreas protegidas no contexto urbano. Na eminente caracterização do histórico e da gestão atual do uso público na UC, foram utilizados dados obtidos por meio de revisão bibliográfica e documental, assim como entrevistas junto aos administradores da área e usuários. Esses dados foram coletados entre julho e outubro de 2011, durante o processo de diagnóstico em direção à elaboração do plano de manejo da UC.

Na finalidade de compreender o perfil dos visitantes, seus hábitos e percepção em relação ao PEPB, foi aplicado, como instrumento de coleta, um questionário contendo 19 perguntas objetivas e subjetivas a 203 pessoas, representando parte da amostra acidental e não probabilística de, aproximadamente, $2 \%$ do total de visitantes registrados no Parque no ano 2010.

O questionário elaborado como instrumento de pesquisa, visou entender melhor a re- 
alidade dos atuantes, diretamente no local estudado, e esse instrumento foi enviado por e-mails destinados a três funcionários e 32 voluntários atuantes no PEPB, ou seja, representando uma amostra não probabilística intencional. $\mathrm{O}$ questionário aplicado foi complementado por carta de apresentação da pesquisa e um glossário.

Assim, a porção de pessoas entrevistadas é composta por 35 profissionais com participação na gestão do PEPB, por serem ativamente engajados no voluntariado, pois são mais indicados no fornecimento de dados necessários ao alcançar o objetivo deste trabalho, e cujos e-mails de contato foram disponibilizados pelos gestores do Parque. Entre os 35 profissionais contatados, 13 deram retorno, concluindo-se, assim, o interesse deles em participar da pesquisa.

Os questionários foram preparados à luz da literatura apresentada, sessões anteriores ao trabalho e a participação ativa dos pesquisadores nas reuniões de Câmara de uso público acontecidas no PEPB - Sede Pau da Fome.

$\mathrm{O}$ contato junto aos voluntários e funcionários do PEPB iniciou-se em 8 de janeiro 2017. Nessa ocasião, foi feito o convite na reunião de Câmara de Uso Público, enfatizando o objetivo da pesquisa de cunho acadêmico com possíveis contribuições voltadas à sociedade, e especialmente, à melhoria do processo de gestão do PEPB.

No objetivo de preservar o sigilo e a confidencialidade de opiniões e as identidades referentes aos entrevistados, foi utilizado o modelo de identificação por números em que não foram mencionados os referidos nomes, de forma a não divulgar informações pessoais de tais respondentes.

O questionário apresentado neste trabalho é constituído por 4 perguntas subjetivas e 2 perguntas objetivas ordenadas em 8 seções. O início do questionário denominado "Dados Gerais" contém perguntas cujas respostas permitem caracterizar o perfil sócio-demográfico dos profissionais (grau de escolaridade e tempo de trabalho como voluntários).

Dando continuidade ao questionário, foram apresentadas perguntas para a caracterização dos atrativos do parque e perguntas relacionadas a informações sobre o uso público do parque, além de acessibilidades arquitetônica e instrumental. Na última sessão, o objetivo foi obter informações relacionadas às sugestões em relação ao aumento da demanda e à caracterização da potencialidade, constituídas de perguntas sobre grau de importância acerca da ótica dos entrevistados, associadas à percepção sociocultural.

Além da opinião de tais indivíduos, enquanto funcionários e voluntários, explorou-se ainda a visão pessoal de cada entrevistado acerca do tema proposto e a importância do assunto em sua vida pessoal e profissional.

Dessa forma, o presente artigo está estruturado em seis seções a contar da introdução, apresentando a visão geral do assunto abordado no decorrer do trabalho. Na segunda parte, é apresentada a metodologia, as ferramentas e os aspectos metodológicos utilizados. A terceira parte diz respeito ao referencial teórico e traz autores que dão fundamento ao estudo. Nessa parte, é exposto o tema turismo ambiental, sendo ele a exploração do meio ambiente em busca de novas experiências e descobertas que promovam transformações. A quarta parte foca-se nos resultados e nas discussões, em que se estabelecem as fundamentações e a construção do tema. $\mathrm{Na}$ quinta parte, è feita a apresentação da estrutura em que está o objetivo geral do trabalho. Na sexta parte, estão as considerações finais.

\section{O DESENVOLVIMENTO DE ATIVIDADES TURÍSTICAS EM UNIDADES DE CONSERVAÇÃO}

Nesta seção, são estabelecidas as fundamentações da construção do referencial teórico, o qual conduziu o alcance dos objetivos propostos neste estudo. Inicialmente, são apresentados conceitos sobre o turismo, sendo este atividade dependente do desempenho de diversas áreas produtivas e setores públicos e privados em busca por satisfazer, de maneira eficiente, à demanda dos usuários. Segundo Molina e Rodriguez (2001, p. 81) "à medida que cresce o interesse em conhecer mais a natureza, na mesma proporção, maior informação é requerida para satisfazê-lo." 
No processo da criação e implementação de UCs ao redor do mundo, mostra-se um legado de conflitos entre os atores envolvidos. No cenário ideológico e político, as posições individuais de ambas as partes acirram o interesse coletivo e individual, ceifam a conservação, ficando, assim, no campo da simbologia ideológica.

O Parque Estadual da Pedra Branca é um exemplo de unidade de conservação integral que apresenta complexidade específica e emblemática de contradições, possibilidades e conflitos entre os propósitos, bem-intencionados, de conservação da natureza, e os objetivos de desenvolvimento econômico e social são promovidos por diversos agentes públicos e privados.

Essa recomendação objetiva que as ações de comunicação e educação ambiental estejam alinhadas com a gestão da UC, estimulando a articulação de gestores federais, estaduais, municipais e a sociedade civil na implementação de processos educativos que promovam o protagonismo social na gestão pública da biodiversidade.

\subsection{TURISMO AMBIENTAL}

O ser humano explora o meio do qual faz parte em uma relação inerente, na busca por experimentar novas sensações, na curiosidade de encontrar algo ainda não visto, sentido ou explorado anteriormente, satisfazendo e/ou alimentando o desejo de querer ser, de saber e de fazer sempre mais. Esse ciclo de procuras e conquistas é relevante pelo simples fato de o ser humano ser inconcluso e estar sujeito às novas aprendizagens que se somam às experiências, sempre promovendo transformações.

Consequentemente, é imprescindível o cumprimento da legislação ambiental, como o que recomenda a Política Nacional de Educação Ambiental: inserir a educação ambiental nos planos, nos programas e projetos voltados ao desenvolvimento das atividades de turismo e de lazer.

Segundo Philippi e Pelicioni (2005, p. 6), "a educação ambiental prepara para o exercício da cidadania por meio da participação ativa individual e coletiva, considerando os processos socioeconômicos, políticos e cultu- rais que a influenciam." O lazer, a recreação e o turismo vêm se tornando atividades crescentes na natureza, sendo meios alternativos de fuga dos grandes centros urbanos. São, ainda, grandes apropriadores do espaço, tornando-o seu principal objeto de consumo.

Nesse ponto, privilegiam-se a aquisição do deleite e o prazer de seus usuários no desenvolvimento de suas atividades, buscando, idealmente, a articulação com novos conhecimentos sobre a preservação/conservação do meio ambiente.

\subsection{ECOTURISMO}

Diversos pesquisadores brasileiros, entre eles Sinay et al. (2017), Trotta, Grechi e Carvalho (2017), Souza e Trevelin (2016), Santos e Marinho (2016) pesquisam o ecoturismo e a sustentabilidade no cenário nacional. Em especial, no Brasil, existe a Revista Brasileira de Ecoturismo - RBEcotur, uma publicação científica produzida pela Sociedade Brasileira de Ecoturismo - SBEcotur, criada em 2008 e que publica, semestralmente, artigos inéditos sobre a temática, colaborando, assim, com o fomento, o diálogo e a difusão de pesquisas em ecoturismo e atividades afins.

Ao buscar experiências práticas e aliar o conteúdo a respeitados especialistas, empreendedores e cientistas da área, pretendemos atrair de forma cativante para a maturidade que o segmento do ecoturismo atinge no Brasil nesse momento. Contudo, ainda há muito que avançar e, nesse sentido, é nossa esperança que o conhecimento aqui exposto ajude aos que se iniciam no setor (SABINO, 2012, p. 17).

Para entendimento e avaliação detalhada desse quadro, torna-se necessário manipular um grande volume de dados e informações prontamente utilizáveis, em escala apropriada, no sentido de realizar o planejamento das ações e a tomada de decisões em bases confiáveis, principalmente no que diz respeito ao manejo de trilhas, principal veículo de condução do 
turismo na natureza. É preciso ressaltar que, nesse exemplo, de uso do geoprocessamento no planejamento do ecoturismo é demonstrado nas áreas de atrativos e informações com as respectivas características ambientais de uma das mais importantes unidades de conservação do município do Rio de Janeiro, o Parque Estadual da Pedra Branca.

O ecoturismo pode ser considerado como uma das poucas modalidades que viabiliza a recuperação das áreas degradadas. Desse modo, é importante levar em consideração a participação de vários atores sociais, voluntários, visitantes / turistas. Ações de reflorestamento, limpeza de trilhas e colaboração na manutenção da infraestrutura de apoio à visitação traduzemse em formas variadas e simples de integrar lazer e conservação ambiental.

Destarte, o ecoturismo pode ser definido sendo o segmento da atividade turística que utiliza, de forma sustentável, o patrimônio natural e cultural, incentiva sua conservação e busca a formação da consciência ambientalista por meio da interpretação do ambiente, promovendo o bem-estar das populações envolvidas, conforme descreveu Crisóstomo (2004).

No universo analítico sobre o significado de ecoturismo, são utilizados diversos termos: "turismo de natureza", "turismo responsável", "turismo verde", "turismo ecológico", "turismo ambiental", "turismo sustentável", e estes se apresentam de formas semelhantes e, até mesmo, idênticas. Por isso, a opção do ecoturismo pela prática em Áreas Naturais Protegidas (ANPs) é considerado, por alguns autores um tipo especial de turismo na natureza.

\subsection{UNIDADES DE CONSERVAÇÃO}

Não considerar as consequências ambientais no desenvolvimento da atividade significa destruir os diversos recursos apreciados por turistas. Conservação é um exemplo clássico das decisões individuais do investimento, conduzindo não necessariamente ao benefício social máximo. A gerência pode estabelecer a escala prática que avalie o aspecto organizacio- nal e legislativo, especialmente quando se trata do uso público em áreas naturais protegidas, as chamadas Unidades de Conservação, que são conceituadas pelo Sistema Nacional de Unidades de Conservação - SNUC da seguinte forma:

Espaço territorial e seus recursos ambientais, incluindo as águas jurisdicionais, com características naturais relevantes, legalmente instituídos pelo Poder Público, com objetivos de conservação e limites definidos, sob regime especial de administração, ao qual se aplicam garantias adequadas de proteção (BRASIL, 2000, online).

Entretanto, depende de participação, fazendo, assim, todo o esquema da análise ambiental com um objetivo sério de conservação. Destaca-se, assim, que o objetivo principal da análise ambiental é conservar e melhorar o ambiente, ou seja, permitir o uso das unidades de conservação mediante a implementação de um segmento de turismo responsável, conforme apregoa Oliveira:

Segmento do turismo concebido através do planejamento comunitário participativo em unidades de conservação da natureza, dentro das limitações impostas pelo seu plano de manejo, compatível com a capacidade de suporte dos ambientes naturais, considerando-se as condições socioculturais e econômicas e respeitando e valorizando as especificidades locais ao desenvolver as atividades turísticas de modo inclusivo. (OLIVEIRA, 2005, p. 33).

É nesse contexto que Lockwood (2010) cita diversos valores associados à existência das áreas naturais protegidas, sendo os principais: suporte à vida, valores econômicos, valores recreativos, valores científicos, valores estéticos, valores de biodiversidade, valores históricos, simbolismo cultural, vida, valores religiosos e filosóficos. Infelizmente, nem todos esses valores são difundidos pelos responsáveis por sua gestão 
e reconhecidos pela maioria da população, o que dificulta a criação da extensão de rede de apoio a essas áreas e a sua priorização no âmbito de políticas públicas no país. A conservação é um ultimato à moral e, assim, na prática, exige uma posição política baseada na instrução, na consciência e na aceitação da necessidade da utilização dos recursos disponíveis.

Segundo Sinay, Sinay e Pena (2014), embora as atividades de turismo e lazer tendam a causar impactos negativos muito menos relevantes do que as atividades anteriores a abertura desta UC ao uso público, a visitação desordenada pode dar sinais de inconformidades, tais como o alargamento das trilhas e o aumento na geração do lixo.

Sobre as afirmações citadas, a gestão de áreas protegidas em nosso país, por si só, já representam um imenso desafio. Quando elas estão localizadas em ambiente urbano, isso tende a aumentar, pois a diversidade de pressões e ameaças a que estão expostas são ainda maiores. Pitt e Boulle (2010) discutem esse tema, apontando que o crescimento das cidades, principalmente, em países em desenvolvimento ou emergentes, tem ocorrido sem planejamento e, muitas vezes, avançado sobre áreas ambientalmente sensíveis, onde geralmente se localizam em áreas protegidas.

Conforme se pôde constatar, no Brasil, apesar de já existirem grupos de estudos sobre a temática, a discussão tem avançado pouco, e não existem políticas públicas específicas que fortaleçam e valorizem as áreas protegidas urbanas, sendo necessário ampliar os esforços em sua inclusão nas agendas da União, Estados e Municípios.

\section{PARQUE ESTADUAL DA PEDRA BRANCA - PEPB}

Criado em 1974, com, aproximadamente, 12.500 hectares de área coberta por vegetação típica da Mata Atlântica, sua dimensão é quatro vezes maior ao Parque Nacional da Tijuca. Nele fica o ponto mais alto da cidade, o Pico da Pedra Branca, com 1.024 metros de altitude. Os acessos ao PEPB podem ser feitos pelos núcleos: Pau da Fome (Taquara), Piraquara (Realengo), Núcleo do Camorim (Jacarepaguá), Posto da Vargem Grande e Posto do Rio da Prata.

Entre as trilhas mais conhecidas, está a trilha com o nome do Parque, a qual vem a ser o ponto mais alto da cidade. Cerca $11 \mathrm{~km}$, dependendo do ritmo, a caminhada pode levar de três a quatro horas de duração. Na figura 1, apresentada abaixo, está o mapa de relevo indicando a localização do PEPB na Zona Oeste da cidade do Rio de Janeiro - RJ.

Figura 1 - Relevo

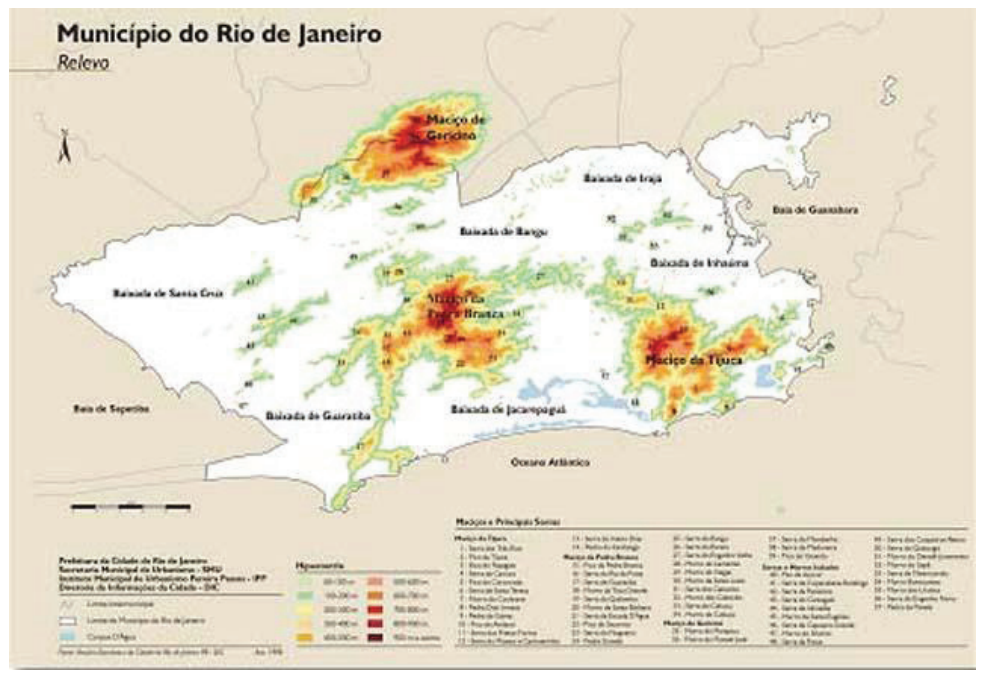

Fonte: (AMIGOS DO PARQUE DA PEDRA BRANCA, 2017, online). 
O Parque Estadual da Pedra Branca PEPB, se trata de uma unidade de conservação urbana, sendo a sua localização a Zona Oeste do município do Rio de Janeiro, compreendendo todas as encostas do Maciço da Pedra Branca acima da cota de $100 \mathrm{~m}$. São $125 \mathrm{~km}^{2}$, fazendo divisa com a Baixada de Jacarepaguá, área urbana que abrange diversos bairros, destacando-se Jacarepaguá, Marechal Hermes, Bangu, Campo Grande, Vargem Grande, Taquara, Recreio dos Bandeirantes e Guaratiba.
O Parque sofre intensa pressão urbana. Porém, presta grande serviço à população carioca, pois nele ficam as represas do Pau da Fome, do Camorim e do Engenho Novo. Dispõe ainda de várias opções de trilhas e passeios ecológicos, sendo considerado um dos maiores parques naturais urbanos da cidade.Destaca-se por ter sua área coberta por vegetação típica da Mata Atlântica. Já na figura 2 mostra-se a extensão do PEPB, que ocupa pouco mais de 10\% do município.

Figura 2 - Área do PEPB

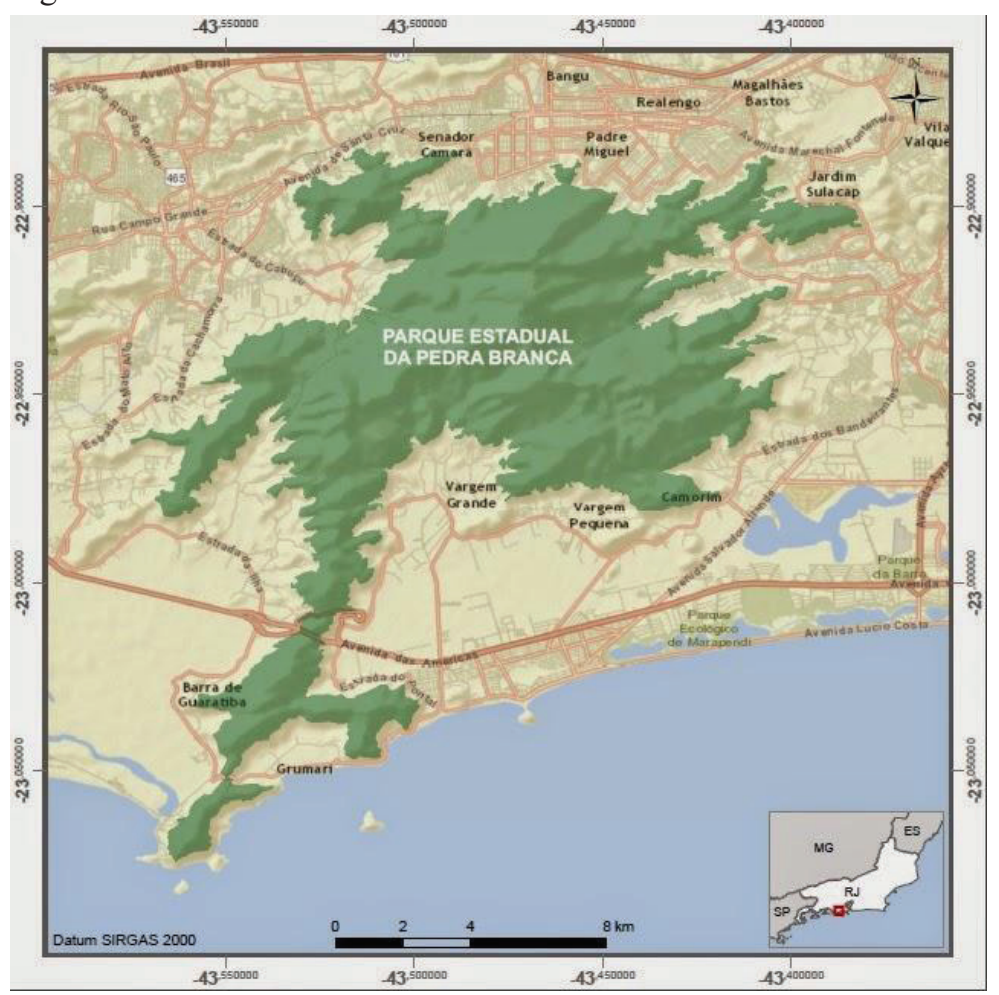

Fonte: (JULIO, 2015, online).

Segundo Costa, Triane e Costa (2008), a área do Maciço da Pedra Branca comporta a maior área protegida do município do Rio de Janeiro. No entanto, a UC carece de estudos detalhados sobre as trilhas, tendo como foco de avaliação a sua vulnerabilidade natural à ocorrência de impactos, sua capacidade de suporte à visitação e suas potencialidades.

Durante a coleta de dados in loco, os pesquisadores tiveram a oportunidade de participar de reuniões nas quais foram apresenta- das informações sobre a gestão do parque. As reuniões aconteciam de três em três meses, na sala multiuso do PEPB - sede da Fome, situada na Estrada do Pau da Fome, no 4003, Taquara, Rio de Janeiro. Estas reuniões contaram com a participação do gestor administrativo, da coordenadora da câmara de uso público, dos guarda - parques e de voluntários.

Assim, no próximo capítulo, apresentam-se e discute-se as informações colhidas na reunião do dia 30 de setembro de 2017 (figu- 
ra 3), que teve os seguintes assuntos pautados: Programa de Voluntariado; Apresentação de adotantes nas trilhas do PEPB, dos seus respectivos trechos de intervenções já realizadas e as próximas a serem efetuadas; Sinalização dos trechos; Apresentação de projetos voltados ao uso público; Ordenamento turístico nas trilhas: Pedra do Telégrafo, Pedra do Osso e Jesus Vem;
Renovação do Termo de Adoção; Implantação da placa do Quilombo do Camorim; Implantação das placas de identificação de núcleos familiares tradicionais; Placa de Identificação; Pontos históricos e turísticos; I Fórum das receptivas Unidades de Conservação da Baixada de Jacarepaguá; Informes gerais.

Figura 3 - Reunião da câmara de uso público do PEBP

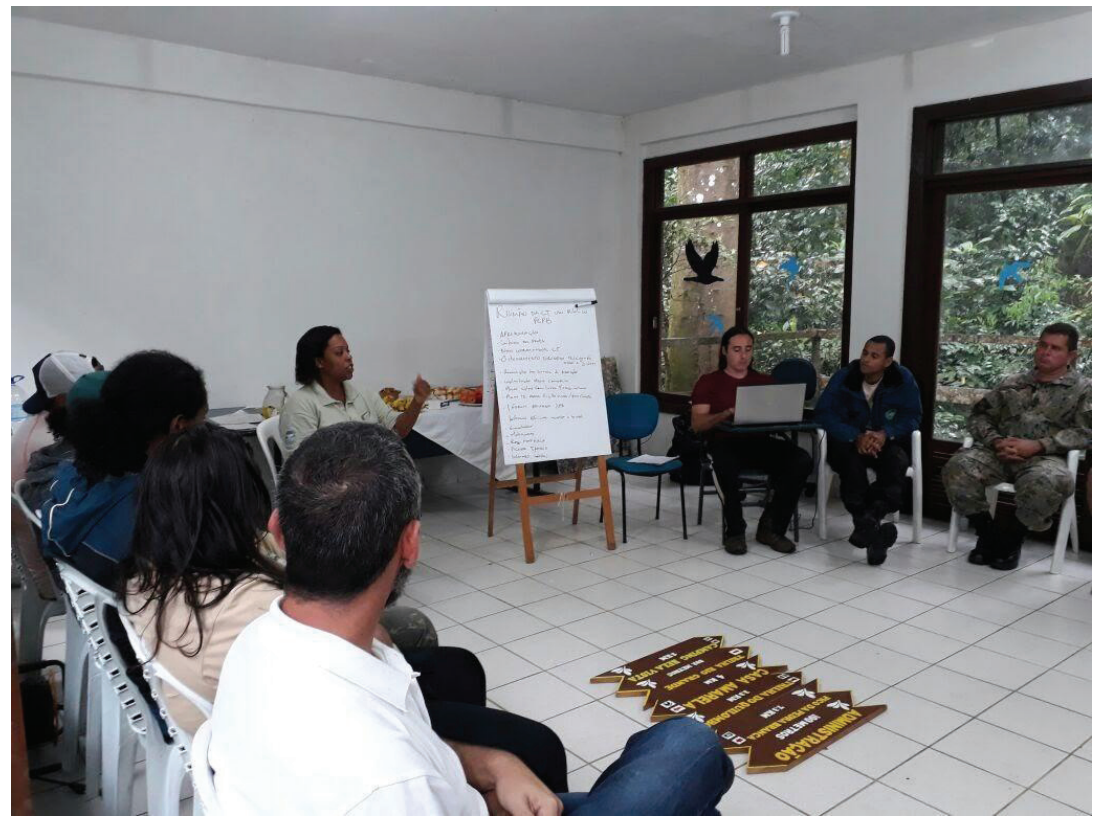

Fonte: os autores.

\section{RESULTADOS E DISCUSSÕES}

O Parque Estadual da Pedra Branca leva o nome do maciço, e sua atribuição se dá à formação calcária, de cor branca, presente no local. No processo de sua revitalização, a sede do parque ganhou a exposição permanente "Da Pedra Branca ao Pau da Fome", visando sensibilizar, principalmente, os estudantes. A mostra era composta por informações sobre a composição das rochas do local, os animais habitantes da região, além de curiosidades sobre a flora, sendo realizada na casa projetada pelo renomado arquiteto Zanini, sendo que esta termina nos viveiros (um minhocário e um bromeliário) especialmente criados de forma a complementar o passeio.

Outro ponto observado na coleta de dados é que os gestores das unidades de conservação prescrevem a proteção do sistema solo-água-vegetação por meio de diagnósticos detalhados, tendo foco sobre o bioma (fauna e flora), porém ainda não consideram as trilhas, veículos condutores de conservação do meio ambiente local.

Neste contexto, constatou-se que o Parque Estadual da Pedra Branca oferece oportunidades ainda insuficientemente exploradas de caminhadas de curta e média duração no Maciço da Pedra Branca, que é recoberto por florestas ou áreas em processo de reflorestamento -, ou seja, um extenso tapete verde encravado na Zona Oeste da Cidade do Rio de Janeiro. Além disso, 
o PEPB possui diversos poços, cachoeiras e sítios históricos, sendo estes ainda desconhecidos da maior parte da população da cidade.

Desta forma, os dados coletados demonstram que, referente ao grau de escolaridade exposto no gráfico 1 apresentado abaixo, $46 \%$ dos visitantes têm nível superior completo, $39 \%$ ensino médio completo e $15 \%$ têm pós-graduação.

Gráfico 1 - Formação dos visitantes

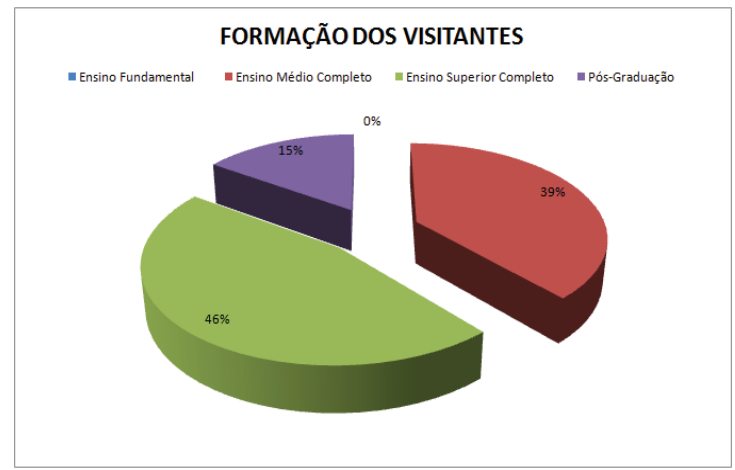

Fonte: dados da pesquisa (2017).

Quanto ao tempo de freqüência dos visitantes ao parque, verificou-se que $38,46 \%$ o frequentam de 1 a 2 vezes ao ano, que $30,77 \%$ o visitam 2 a 5 vezes ao anos mesmo percentual apresentado pelo público que visita o parque 5 a 10 vezes ao ano.

Gráfico 2 - Tempo de frequência

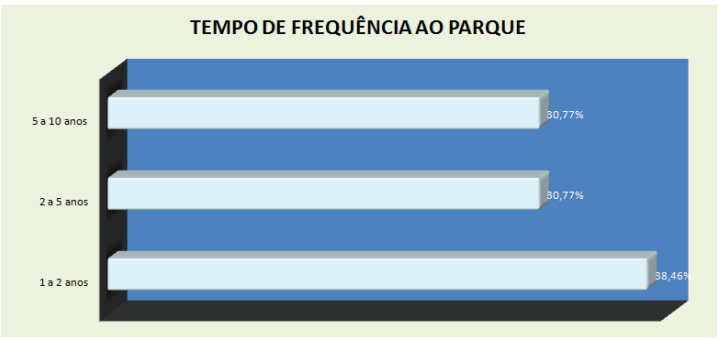

Fonte: dados da pesquisa (2017).

Referentes aos dados sobre a motivação dos visitantes, estes consideraram como principais os seguintes atrativos do parque: $22 \%$ dos pesquisados afirmaram que o procuram por natureza, $21 \%$ por suas trilhas e flora, 19\% para visitar as suas cachoeiras, e, por fim, 17\% para a observação da fauna.
Gráfico 3 - Atrativos do Parque

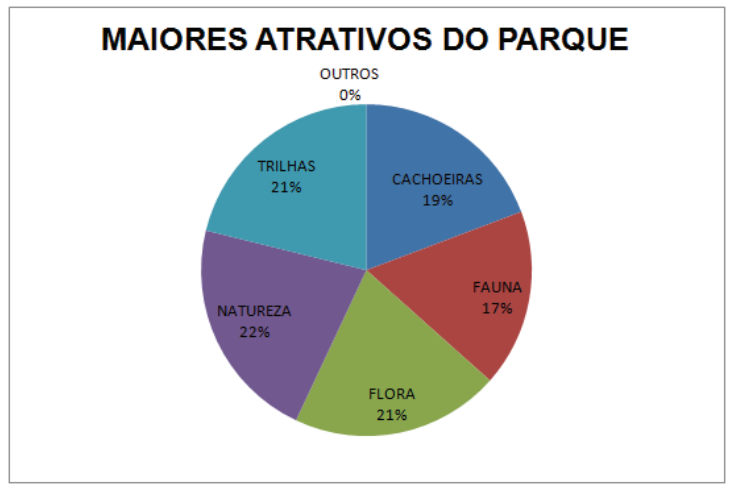

Fonte: dados da pesquisa (2017).

Os resultados das entrevistas com os visitantes do PEPB permitem traçar um perfil inicial dos usuários do Parque. Esses usuários identificam, com bastante propriedade, vários dos principais problemas relacionados à gestão do uso público nesta UC, e ainda, fazem propostas que devem ser analisadas, cuidadosamente, pela administração da área. Transcreve-se, a seguir, algumas das respostas que contextualizam a opinião dos entrevistados.

"Gostaria que o poder público tivesse mais interesse por esse patrimônio tão rico que é o PEPB."

"Atualmente, o Rio de Janeiro passa por um momento crítico na área de segurança pública, sugiro a viabilidade de implantar um posto do Batalhão de Polícia Florestal dentro ou próximo ao parque."

"Ampla divulgação do parque e realização de mais eventos sobre educação ambiental". Referente à estrutura e à acessibilidade do PEPB, mediante os dados coletados na pesquisa de campo com os entrevistados, constata-se que:

- Quanto ao transporte público: 7 dos usuários classificaram como bom, 1 muito bom, 4 muito ruim e 1 não se aplica;

- Quanto à segurança oferecida aos visitantes: 1 muito bom, 8 bom, 3 muito ruim e 2 não se aplica;

- Quanto à limpeza do PEPB: 1 muito bom, 9 bom,1 muito ruim e 1 não se aplica;

- Quanto à alimentação oferecida no local: 1 muito bom, 1 bom, 8 muito ruim e 3 
não se aplica;

- Em relação à acessibilidade instrumental: 9 bom, 1 ruim, 2 muito ruim e 1 não se aplica;

- Acessibilidade arquitetônica: 1 muito bom, 4 bom, 7 ruim e 1 não se aplica.

Diante das informações obtidas, foi possível compreender melhor a atividade e os mecanismos que cercam a gestão das respectivas unidades de conservação. Assim, pôde-se inferir que a região é propícia à prática do ecoturismo devido ao fato de sua localização ser no interior de uma Área de Proteção Ambiental, de estar localizada em uma área urbana e de fácil acesso.

Tais características permitem a formação de investigações que avaliem o nível de fragilidade dos locais de maior potencial e desenvolvimento dessa modalidade de turismo, subsidiando a implementação do uso público no contexto do manejo da área protegida. Além disso, a presença de recursos naturais possibilita ao visitante o contato direto junto à natureza e potencializa atividades contribuintes na geração de renda, emprego e aumento da qualidade de vida da população de entorno, sem prejuízo à conservação ambiental.

\section{CONSIDERAÇÕES FINAIS}

A presente pesquisa foi desenvolvida por meio de levantamento bibliográfico, visitas in loco e questionário destinado a 25 voluntários, visando ao objetivo de analisar a percepção da comunidade acerca da atividade de ecoturismo desenvolvida no PEPB. Diante do exposto, este trabalho, seja na partida buscando o engajamento de mais alunos ou pesquisadores, visou favorecer possibilidades de crescimento e melhorias no que diz respeito ao desenvolvimento das atividades turísticas no parque, de forma a agregar particularidades de conservação, contribuindo, assim, para transformar bons hábitos em realidade.

Essas questões podem ser alcançadas por meio da participação de empresários da cadeia produtiva do turismo, uma vez que, por meio deles, podem-se obter parcerias públicas e privadas, incentivando a valorização das questões ambientais, a valorização da cultura local, o aumento das visitações na região e a divulgação da localidade, valorizando a biodiversidade presente na área. Além disso, intentou-se incentivar o desenvolvimento de políticas públicas por meio do governo, e que estas incentivam melhorias na localidade de forma geral, visto que esses locais são vistos como oásis esquecidos das grandes metrópoles.

Desse modo, este trabalho pode gerar benefícios para o $\mathrm{PEPB}$, pois possibilita às pessoas conhecerem o Parque e suas histórias, estimulando-as a conservá-lo, contextualizando a oportunidade de aprender sobre sítios geológicos e culturais únicos; conhecendo e resgatando sua história; entendendo as dinâmicas ambientais na sua importante relação com a cidade e seus habitantes. Dessa forma, é possível criar consciência ambiental e cultural de apreciação à paisagem da Cidade do Rio de Janeiro, tendo uma experiência natural nesse ambiente preservado em meio à urbanização. Diante da importância da demanda, é necessário que, junto ao período de elaboração do Plano de Manejo de UCs, sejam determinados no Plano de Uso Público as capacidades de carga e o seu limite de visitantes

Com grande parte da UC fazendo limites com bairros da baixada de Jacarepaguá, Pau da Fome (Taquara), Piraquara (Realengo), Núcleo do Camorim (Jacarepaguá), Posto da Vargem Grande e Posto do Rio da Prata, ocupados por moradores que possuem baixa renda, esse Parque pode servir, ainda, como uma opção de lazer e recreação aos moradores de comunidades mais carentes, revelando um imenso valor social.

Além destes atributos, destaca-se a possibilidade do visitante ter contato direto com a natureza, sendo que estes visitantes potencializam atividades que contribuem na geração de renda, emprego e aumento da qualidade de vida, sem prejuízo à conservação ambiental. Vale mencionar que partir de 2010, o PEPB deu início a investimentos na reestruturação de seu uso público, e novas pesquisas devem ser realizadas de forma a avaliar o impacto dessas ações na quantidade da visitação, seja recreativa ou educativa. 
Assim, o estímulo à visitação no PEPB, desde que ordenada, poderá contribuir na sensibilização de grande número de pessoas, disseminando conceitos sobre conservação da natureza e angariando parceiros em defesa das causas ambientais e proteção desta UC. Além disso, poderá tornar-se fonte de geração de renda na UC e contribuir no desenvolvimento local, com o estímulo ao fornecimento de serviços aos visitantes. Entretanto, é necessário que as comunidades localizadas nos bairros e entorno consigam enxergar seu potencial e fortaleçam sua identidade como comunidade, tornando-se, assim, defensores de seu patrimônio.

\section{REFERÊNCIAS}

AMIGOS DO PARQUE ESTADUAL DA PEDRA BRANCA. Núcleo Pau da Fome. Disponível em: www.parquepedrabranca.com $/ \mathrm{p} /$ nucleo-pau-da-fome.html. Acesso em: 10 set. 2017.

BRASIL. Rio de Janeiro. Instituto Estadual do Ambiente - INEA. Disponível em: http://www. turismo.gov.br. Acesso em: 9 jun. 2020.

BRASIL. Lei $\mathbf{n}^{0}$ 9.985, de 18 de julho de 2000. Regulamenta o art. 225, § 1丷ㅡㄴ incisos I, II, III e VII da Constituição Federal, institui o Sistema Nacional de Unidades de Conservação da Natureza e dá outras providências. Brasília, DF: Presidência da República, 2000. Disponível em: http://www.planalto.gov.br/ccivil_03/leis/ 19985.htm. Acesso em: 21 maio 2020.

COSTA, V. C.; TRIANE, B. P.; COSTA, N. M. C. Impactos ambientais em trilhas: agricultura $\mathrm{x}$ Ecoturismo - um estudo de caso na Trilha do Quilombo (PEPB-RJ). Revista Brasileira de Ecoturismo, 2008.

CRISÓSTOMO, F. R. Turismo \& Hotelería. [S.l.]: Dcl, 2004.

FIDELIS, P. Rio de Janeiro e São Paulo são as mais visitadas por estrangeiros. 2016. Dis- ponível em: http://www.turismo.gov.br. Acesso em: 8 set. 2017.

JULIO. Aventura Turismo. 2015. Disponível em: http:/www.aventritur.com.br/2015/03/ acude-camorim.html Acesso em: 10 set. 2017.

LOCKWOOD, M. Good governance for terrestrial protected areas: A framework, principles and performance outcomes. Journal of Environmental Management, v. 91, p. 754-766, 2010 .

MOLINA, S; RODRIGUEZ, S. Planejamento integral do turismo: um enfoque para a América Latina. [S.l.]: EDUSC, 2001.

OLIVEIRA, S. D. Certificação de Atividades Turísticas Responsáveis em Unidades de Conservação. Estudo de Caso: o Parque Estadual Morro do Diabo, Pontal do Paranapanema, SP. Programa de Pós Graduação em Engenharia de Produção e Sistemas. Florianópolis: UFSC, 2005.

ORGANIZAÇÃO MUNDIAL DO TURISMO. Agenda para Planificadores Locales: turismo sostenible y gestión municipal. Edición para América Latina y El Caribe. Organización Mundial del Turismo: Madrid, España, 1999.

PHILIPPI, J, A.; PELICIONI, C. F. Bases políticas, conceituais, filosóficas e ideológicas da educação ambiental. Educação ambiental e sustentabilidade, 2005.

RIO DE JANEIRO. Decreto Estadual $\mathbf{n}^{0}$ 42.483, de 27 de maio de 2010. Estabelece diretrizes para o uso público nos parques estaduais administrados pelo instituto estadual do ambiente - INEA e dá outras providências. Rio de Janeiro, 2010.

RUSCHMANN, D. V. M. Turismo e planejamento sustentável: a proteção do meio ambiente. [S.l: s.n.], 2004. 
SABINO, J. (org). Ecoturismo: Nas trilhas da biodiversidade brasileira. [S.l.]: Editora Natureza em Foco, 2012.

SANTOS, F. N; MARINHO, L. Turismo, Sustentabilidade, Desenvolvimento Local e a Questão do Turismo Litorâneo. Revista Acadêmica Observatório de Inovação do Turismo, v. 10, n. 2, p. 67-82, 2016.

SINAY, L.; SINAY, M. C. F.; PENA, I. A. B. Parque Natural Municipal da Paisagem Carioca (RJ): ecoturismo e sustentabilidade. Revista Brasileira de Ecoturismo, São Paulo, v. 7, n. 3, p.500-516, ago./out. 2014.

SINAY, L.; SINAY, M. C. F.; PASSOS, F. V. A.; BRAGA, I. L. Megaeventos, legado e sustentabilidade: o caso da Cidade do Rio de Janeiro. Revista Brasileira de Ecoturismo, São Paulo, v. 10, n. 3, 2017.

SOUZA, C. A; TREVElin, A. C. Turismo Responsável: o caso de Bonito/MS. Revista Acadêmica Observatório de Inovação do Turismo, v. 10, n. 2, p. 50-66, 2016.

TROTTA, A; GRECHI, D. C; CARVALHO, E. M. Geopark Bodoquena-Pantanal: análise da inserção do Núcleo de Nioaque, Mato Grosso do Sul. Revista Brasileira de Ecoturismo, v. 10, n. 3, 2017.

VERGARA, S. C. Projetos e Relatórios de Pesquisa em Administração. 4. ed. São Paulo: Atlas, 2003. 